\title{
Assessing the Governance and Transparency of National Public Pension Funds
}

\author{
Pablo Souto \\ Center for Financial Stability, Argentina \\ E-mail: psouto@cefargentina.org
}

Alberto R. Musalem (Corresponding author)

Center for Financial Stability, Argentina

Luis Agote 2445, 4th floor (C1425EOE), Ciudad Autónoma de Buenos Aires, Argentina

Tel: 54-9-11-379-621-84 Email: albertoroque.musalem@gmail.com

$\begin{array}{lr}\text { Received: March 28, } 2012 & \text { Accepted: April 30, } 2012 \quad \text { Published: June 1, } 2012 \\ \text { doi:10.5539/res.v4n2p148 } & \text { URL: http:/dx.doi.org/10.5539/res.v4n2p148 }\end{array}$

We greatly acknowledge the insightful comments by Robert Holzmann and Mark Dorfman from the World Bank, and Dimitri Vittas. We are grateful to the World Bank for having sponsored this research. The usual disclaimer applies.

\begin{abstract}
Full or partial funding of traditional public pension schemes becomes crucial for the inter-temporal sustainability of the systems. A good governance structure for national public pension funds (NPPFs) may work as a deterrent for misuse of the assets of the fund, which are particularly exposed to abuse by governments. Our study provides the first global comprehensive survey on governance, transparency, assets, and investments of 83 NPPFs located in 68 countries. We develop and calculate a Transparency and Governance Index that measures compliance of NPPFs with best practices. Our results indicate a wide dispersion in governance and transparency performance of these funds, and provide the basic elements that governments should take into account when reforming NPPFs' governance structures.
\end{abstract}

Keywords: Publicpension funds, Governance, Transparency, Financial intermediaries

\section{Introduction}

Public pension regimes have traditionally been of the pay-as-you-go (PAYG) type, and the role of accumulated reserves has been overlooked. Even more, pension funds management is mostly associated with private entities managing contributions of plan members.

This is very striking in light of the actual relevance that public pension reserves managed by governments play in a number of countries. Figures as of 2007, show that national public pension funds (NPPFs) managed assets globally by about USD 4.4 trillion equivalent. This is a conservative assumption, since our survey does not cover the complete population of NPPFs. Furthermore, our survey found several other countries for which there is no information on assets under management for that year, hence a true number is well above our estimate. In fact, assets of NPPFs around the globe represent a much larger number than those managed by Sovereign Wealth Funds (SWFs), whichrecently have attracted much attention from policy-makers and the media around the world.

The data also hinder quite particular asymmetric situations in terms of the actual importance of NPPFs in the local economies. On the one hand, in 2007, assets of NPPFs in Norway and Namibia accounted for 94\% and 64\% of GDP, respectively, while on the other hand, there are a number of countries -namely Colombia, Kazakhstan, 
Mexico, and the Czech Republic among others- where NPPFs'assetsrepresented an insignificant share of the economy, showing ratios of less than $1 \%$ of GDP.

Given that NPPFs have had a minor role for academics and even policy-makers, relatively scarce studieshave been done on their governance structures and even less attempts have been made to systematically and comprehensively measure those structures.The governance frameworks of NPPFs involve elements related to both their role as fund managers and as state-owned entities. Therefore, the importance of high standards of governance for NPPFsshould not be underestimated, considering the impact that the funding of public pension systems is posing on the prospects for payments of retirement benefits, fiscal accounts, financial sector development and long-term economic growth.In addition to the importance of proper use of public monies, some other issues regarding NPPFs are worth noticed. For instance, factual evidence seems to indicate that worst returns are produced by publicly managed pension funds in countries with poor governance records(Iglesias and Palacios, 2000).Again, factual evidence seems to link this poor performance to undue political interference in the investment decision of public funds (explicit mandates or powers of coercion), e.g., explicit social and developmental objectives that undermine financial viability of NPPFs.

Organizational performance is strongly correlated with governance indicators. The way NPPFs are governed has an impact on investment strategies and how assets are invested, which directly affects fund performance (Useem and Mitchell, 2000). The authors find that governance of NPPFs affects performance only indirectly by determining key investment strategies; these strategies are associated in turn with higher performance.

In such a context, the purpose of the paper is to present a survey of the actual governance and transparency practices at the NPPFs existing around the world. The price we pay for undertaking such a comprehensive effort is that we do not go into details about the governance structure of any particular NPPF. Best practices have already been analyzed by a number of authors so we intend to fill the gap existing in terms of looking at NPPFs on a global basis. We acknowledge a previous work by Bebczuk and Musalem (2008) on this subject. However, our work is much more comprehensive than theirs, since it about doubles the sample size of NPPFs, builds time series data instead, and uses different criteria for assessing governance and transparency performance.

The paper has been structured as follows. Section 2 shows quantitative data of the NPPFs that were surveyed. Section 3reviews the literature on governance of NPPFs, deals with the key issues on their governance framework regarded as recommended practices, and presents the main actual governance features of the NPPFs that were surveyed. Section 4 introduces the Transparency and Governance Indexes (TGI) that were calculated for 83NPPFs in 68 countries for which public information was available and accessible through websites; while Section 5 concludes.

\section{Quantitative data of National Public Pension Funds}

\subsection{Size and relative importance}

NPPFs are gaining increasing relevance around the world. The need for the states to:a) keeping the promises embedded into the pension plans sponsored by governments; and $b$ ) assure that public finance will not be put into much stress due to the contingent liabilities that are being assumed in the present, have led countries to set up NPPFs.

Using official websites as the only source of information (being it either the social security administration or a similar official agency in charge of managing NPPFs), we assembledtime series dataon assets under management, investment portfolio composition and fund performance of 83NPPFs in 68 countries for the period 2001-2007, although some have been introduced after 2001.Although certain limitations have come up when assembling the sample, we consider they do not constitute major biases that may affect results and conclusions (Note 1).

Table 1 presents striking features of the data, being them the asymmetries in terms of the publicly available information for three basic indicators that we have surveyed: assets, portfolios' composition, and performance. Two stylized facts are worthy noticed. First, there is a pattern in terms of timeliness of available information. In the three cases, more data is available in the intermediary years (that is, two to four years old), relative to the extreme years (most recent data and the oldest one). This could be partially explained by the fact that, according to official documents released by certainNPPFs, they prefer to disclose information with a lag to avoid being in a competitive disadvantage to other investors. We consider that such practiceis suboptimal, since it makes difficult for outsiders to exert effective monitoring over the use of public resources. Second, for every year, and using the same sources, there is more information available on assets under management than either on portfolios' composition or funds' performance. This should also be a matter of concern provided that ultimately, fund 
managers will be evaluated in terms of the risk-return performance of the fund, yet scarce data is provided on this matter.

As of 2007, assets under managementrecorded USD 4.4 trillion. If we were to add up those funds for which there is available information for previous years the figure would have risen up to USD 4.7 trillion. Interestingly, estimates released by the Sovereign Wealth Funds Institute, indicate that assets under management of this type of entities recorded USD 3.6 trillion, well belowour estimate forNPPFs (Note 2).

Figure 1presents the evolution of assets under management based on the information publicly available through the official websites. Assets under management of NPPFs are extremely concentrated in few countries. Data for 2007 show that the United States Old-Age and Survivors Insurance Trust Fund is the largest NPPF, with assets under management of USD 2 trillion, accounting for $46 \%$ of overall assets under management in that year. If we add up the Japanese NPPF, then they together accounted for $71 \%$ of total assets under management (Figure 2).

In order to put those numbers in perspective, Figure 3 reflects the actual relevance of NPPFs in the national economies, as a proportion of their respective GDP for the year 2006, for which more information is available.It is very interesting to note that 6 out of the 10 NPPFs that were the largest in terms of GDP corresponded to developing countries. As it can be seen, in almost half the countries that were surveyed, NPPFs are very relevant within national economies, managing assets representing over 10\% of their respective GDPs, while in many cases they exhibited an increase in their importance since 2001.

\subsection{The investment portfolio}

With respect to portfolio composition, there is a broad range of investment strategies across the board and also many NPPFs have markedly shifted their portfolio allocation in the last years. Figure 4 presents the global average portfolio for the entire period. The figure is heavily affected by the portfolio composition of the two largest funds, namely the US and Japanese NPPFs that are mostly invested in sovereign bonds. When excluding those two funds, the participation of variable income securities in the composition of the average portfolio of NPPFsalmost triples, and has been growing since 2001.

Despite that trend, NPPFscontinue to be a source of financing for private and sovereign issuers of fixed income securities (bonds), notably the latter. In extreme cases, the NPPFs invest almost entirely in government securities, as it is the case of Colombia (100\%), United States (100\%), Spain (99.7\%), Sri Lanka (98.6\%), and Singapore (97\%). Figures for another group of countries also show relative high levels of exposure to sovereign bonds, such as Costa Rica, Guatemala, Japan, and Sierra Leone. The most notable exception to this stylized fact is South Korea, where itsNPPF invests more than $80 \%$ of its portfolio in fixed income securities, but mostly on corporate bonds.

The undersized local capital markets in developing economies in conjunction with regulatory constraints that restricts investment alternatives, including foreign diversification of the portfolios, and conservatism of board dominated by workers and retirees representation may explain the still relatively low participation of equity in funds' investment portfolios. Mitchell and Hsin (1994) -analyzing a sample of US state and local pension fundsassert that more retirees' representation tends to lower performance due to greater weighting to fixed-income portfolio. In a few cases in developing countries where there are important proportions of equity investments, they correspond to acquisition of foreign stocks (e.g.,Namibia, Swaziland).Moreover, the Swedish AP6, Slovenian NPPS, Ireland, and Swaziland are the NPPFs that are oriented towards holding a larger proportion of stocks, showing figures above $70 \%$.

Finally, certain NPPFs are a source of funding of the banking system through their holdings of cash and bank deposits. The most notorious examplesare those of Australia, Saint Kitts and Nevis, and Saint Vincent and the Grenadines that invest $87 \%, 60 \%$ and $55 \%$ of total assets in cash and bank deposits, respectively.

\section{Key Issues on Corporate Governance}

\subsection{Conflicts of interest in state-owned financial institutions}

Although NPPFs exist since the 1940s, their governance has only recently attracted attention from policy makers and academics (more has been done regarding private pension funds). Indeed, governance regulations of pension funds have not always been present in all countries. Most often, they have been introduced as a response to cases of fraud or misappropriation of pension assets.

Iglesias and Palacios (2000), Impavido (2002), and Musalem and Palacios (2004) areamong the initial works intended to analyze governance of NPPF in a comprehensive way, while Bebczuk and Musalem (2008), and Mitchell et al. (2008) have followed suit. In particular, Iglesias and Palacios (2000) analyzed the link between 
governance and performance. Then, efforts in this regard by multilateral organizations are recent as well, as reflected by the issue of guidelines for the investment of public pension funds by the ISSA (2004). Although the guidelines prepared by the Organization of Economic Cooperation and Development (OECD, 2002) were intended to provide a basis of good governance of private pension funds, a number of elements are relevant for NPPFs as well.There is also an increasing amount of literature on the governance structure of NPPFs that has mainly focused on the comparative analysis of specific cases, mostly those NPPFs located in OECD countries. Bosworth and Burtless (2003), Palacios (2002), Vittas et al. (2008) andYermo (2008) are examples in this regard.

The analysis of the governance structures of NPPFsposes a number of additional challenges given their simultaneous role as financial intermediaries and state-owned entities. Moreover, they intermediate funds whose ultimate beneficiaries have in most cases no specific proprietary rights over them, thereby expanding the scope for potential conflicts of interest that the governance structures should have to tackle and resolve.

Broadly speaking, the key features that differentiate financial intermediaries from non-financial firms are their relative opaqueness, their high leverage levels, the existence of a wide state-promoted safety net, a more complicated management, and the larger asymmetric information problems between insiders and outsiders. In the particular case of NPPFs, opaqueness may be exacerbated in those cases that information about the inflows and outflows of the fund are mingled with the public budget, and no clear guidance exist with respect to it.

The analysis of leverage of NPPFs is an elusive matter. When looking at the actual balance sheets of NPPFs, leverage seems not to be a concern. However, when analyzing the pension scheme in a comprehensive way, future payments to beneficiaries should be considered. Those benefits therefore constitute a contingent liability that is not being recognized in NPPFs balance sheets or in public accounts, at least in the majority of countries. Interestingly, in some cases a good practice of regularly publishing actuarial studies with respect to those liabilities has been established.

Since financial institutions (banks, institutional investors) are intermediaries of third-parties funds with little -if any- own stake at risk, the problems of asymmetric information between insiders (shareholders, boards, managers) and the ultimate beneficiaries (depositors, investors of a mutual fund, affiliates to a pension fund, insurance policy-holders) are exacerbated while at the same time new agency problems arise between the principal (outsider) and the agent (insider).

A solution to this problem has been to establish fiduciary duties for insiders that imply they should act in such a manner aiming to maximize portfolio (risk-adjusted) return. The specific way these duties shall be put in place are still a matter of discussion, although certain features are clearly essential in this regard,namelyhigher standards of transparency, independent boards, internal and externalcontrols, among the most relevant ones. Moreover, the particularities of these fiduciary duties will also depend upon the characteristics of the principal (sophisticated or not, dispersed or not) and the source of funding (mandatory or voluntary). In any case, any or a combination of them implyhigher intermediation costs. As long as they are lower than the benefits derived from their adoption, the society as a whole would be better off.

Another public response to address those conflicts of interest was to set up a regulatory and supervisory framework, under the responsibility of an official agency. This has been particularly the case when the principal (depositors, affiliates) is dispersed and not-sophisticated. When the principal is dispersed, it means that a rational decision for them is not to monitor the agent since they may act as free-riders of others' monitoring activities. However, collective action in this way leads to sub-optimal levels of monitoring. Couple to that, the majority of depositors of a bank and affiliates to a pension fund are mostly unsophisticated agents so the costs for them in terms of resources devoted to dealing with asymmetric information are relatively high in terms of their stake at risk. Ultimately, the incentives for intermediaries to misuse funds are encouraged by the lack of effective monitoring and exert of market discipline.

For financial intermediaries in general the existence of a regulatory framework and a supervisory authority can lead other stakeholders (depositors, investors, and affiliates) to assume a more passive monitoring role. The introduction of the state as a regulator and supervisor is therefore intended to provide this public good in the most efficient way. States have then developed a number of instruments to deal with this, namely prudential regulations, entry barriers in the industry, minimum capital requirements, and transparency standards, in conjunction with a sanction scheme to those breaching the norms. However, this approach creates new potential sources of conflicts such as even less monitoring by large stakeholders in thebelief that there is an implicit state-promoted safety net, the capture of the regulator by the industry, among others. 
According to Bebczuk and Musalem (op.cit.), in the particular case of NPPFs, the typical agency problems that plague all financial intermediation activities are exacerbated whenever the pension plan is run by a government agency because: (a) Plan members may relax their vigilance on the fund provided they perceive contributions as a tax or have the expectation that the government will pay the pension no matter the fund performance; (b) NPPFs do not operate under competitive conditions; (c) Senior managers and directors in government institutions may not be selected on the basis of fit-and-proper criteria but on political affiliation; (d) NPPFs are not subject to the same regulatory framework than private intermediaries and, even if they are, the incentives are distorted as the state is both the regulatorand the regulated party; and (e) The NPPFs managers may want or be mandated by the government (as long as political independence is dubious) to further social goals other than the paramount objective of providing adequate old age income support to plan members. Political goals may include the funding of economically or socially targeted investments, or the development of local capital markets by prohibiting or restricting international diversification. Importantly, in most cases ultimate beneficiaries of the outcome of the fund have no specific proprietary rights over the assets under management so the functioning of typical market discipline mechanisms are severely restricted; beneficiaries are unable to vote with their feet and may only rely on actually voting in political elections.

Hess and Impavido (2004) identify the potential agency problems that are apparent in NPPFs. Ultimately, the development of an effective governance structure aims at efficiently dealing with those problems. For this to be done, it is imperative to first recognize who the relevant stakeholders are. For the authors, in the case of NPPFs the key stakeholders are the plan participants, the government and the tax-payers.

\subsection{Desirable governance and disclosure standards}

In the broadest sense, the task of governance of a pension fund can be conceived as a set of arrangements, including a well-defined legal and regulatory framework for the protection of plan members' interest. A perfect system of governance would give all the parties involved in the operation and oversight of the pension fund the right incentives to act in the best interest of the pension fund members and ensure the highest degree of retirement security.

Consequently, the implementation of a good governance structure for NPPFs becomes an issue of public interest. In this line, Impavido (2002) recognized that the governance of NPPFs is critically important, since the quality and performance of fund management can determine the income flows to which retirees are entitled, as well as the level of government funding of any shortfall between what the plans may promise (if they are defined benefit) and what they are capable of delivering.

After surveying governance practices at NPPFs in OECD countries, Yermo and Marossy (2002) outline a set of recommendations for NPPFs so as to assure that their governance framework best protect the interest of pension plan members or beneficiaries, namely: i) there should be governance regulations that cover the functions and the decision-making process of pension funds; ii) pension plan members and beneficiaries should be granted with mechanisms to monitor those responsible for the management of pension funds; and iii) effective regulation should include a transparent framework for the division of responsibilities in the operation and oversight of the pension fund as well as the accountability and suitability of all parties involved in the pension fund process. Governance regulations must also define the mechanisms for internal control, communication, and redress for pension plan members and beneficiaries.

Within such a framework, Impavido (op.cit.) outlines a specific framework for the analysis of the governance of PPF management, which is basically composed of six elements: i) definition of roles and responsibilities; ii) process for nomination and appointment of board members and senior managers; iii) qualifications for board members and senior managers; iv) accountability; v) internal and external control systems; and vi) transparency and disclosure.We suggest adding the establishment of redress mechanisms. While the first four elements correspond to the governance structure, the last two have to do with governance mechanism.

Some of these regulations (e.g., division of responsibilities, suitability, internal controls) aim at containing conflicts of interest by specifying certain requirements of the legal structure of the pension fund, its governing body and other parties involved in the pension fund process, and the relationship between all these persons and entities. Regulations on accountability, disclosure and redress mechanisms, on the other hand, aim at empowering individuals with monitoring, oversight and disciplining powers over those responsible namely the plan sponsor and the governing body.

This approach and characterization also benefits from the OECD Principles of Corporate Governance (CG) that, although developed in relation to corporations, provide a useful framework for addressing pension fund governance. The basic principles established by the OECD are responsibility, accountability, suitability, control, 
disclosure, and redress. Moreover, Vittas et al. (2008) outline a number of policy recommendations aiming at improving the investment policies of NPPFs, and ultimately their performance. According to the authors, NPPFs should be established only if they can rely on regular transfers of funds and can operate with long investment horizons. The size of the NPPF should not be too large relative to the national economy and local financial markets. However, we would add that if size becomes an issue, there are mechanisms to deal with it (e.g., Sweden adoption of multiple independent funds). Global diversification should be encouraged. The ability to enforce high standards of fund governance is crucial to the success of the new approach to NPPF management.

NPPFs should have clear and unequivocal commercial mandate meaning that the objective and mission of the NPPF should be clearly stated in order to facilitate the adoption of measurable goals against which the performance of the plan - and its governors and administrator - can be measured. The mandate should be to seek to maximize long-term investment returns, subject to a prudent level of risk, and after taking fully into account the structure of its liabilities and length of its investment horizon.

The governance structure and the responsibilities of the persons/entities must be clearly stated in the fund statutes, regulations, by-laws, or contract. Governing functions and responsibilities should be clearly separated from managing functions and responsibilities. Different individuals should belong to each of these groups. In general, it is good governance for the governing body to have only strategic and monitoring responsibilities, with operational tasks being handed over to an executive management team.

The board can be divided into separate committees with clear terms of reference and areas of responsibility, such as for investments, auditing, human resources and compensation, and governance. They should have a process for evaluating their own performance and that of their committees. Outside experts could be recruited to serve on these committees alongside board directors. The board should establish clear guidelines on corporate governance (CG), including rules on conflicts of interest and ethical conduct by directors and senior managers of the fund. It should also establish clear policies on its role in promoting good practices of CG in investee companies.

The process for nomination and appointment of board members and senior managers shall be clearly established so as to assure they are independent from government and insulated from political interference. For instance, a nominating committee should be created to identify a short list of candidates from which the relevant authority (Minister or the like) would make director appointments. The process of director removal should be clearly stipulated in the relevant act.

It is important to ensure that appointed governors have proper credentials and are protected from unduly political interventions that may affect their decision-making processes. There should be a sufficient number of directors with adequate expertise and experience on financial matters, investment policies and portfolio management.

The fund should be subject to full public accountability to Parliament or similar body and its main stakeholders.Accountability criteria to make opportunistic managers liable for their actions shall be established, as long as wrongdoing can be proved in an administrative or judicial court. For accountability to be effective, responsibilities shall be first clearly imposed on a governing body or a person (Maher, 2004). Accountability of the governing body requires also regular meetings, appropriate disclosure of the decisions reached in these meetings to plan members and beneficiaries, and reporting of information about the operation of the pension fund to the supervisory authorities.

Adequate oversight derives from the combination of internal and external auditing, actuarial reviews, and reporting to the Executive and Legislative Powers. Governance regulation may also require the establishment of an oversight committee to control the governing body ("to monitor the monitor").

Also, the ability of outsiders to have a hold over senior managers and directors crucially depends on the flow of reliable information that is disseminated. Maher (2004) stresses the importance of adopting effective accounting and auditing requirements in order to assure the reliability of the information conveyed to stakeholders. Although auditing can be provided internally, it should be provided externally as well. The financial activities of the pension fund must be audited at least on an annual frequency, as well as for compliance with all the rules set out in the pension plan statutes. The auditor should also conduct a periodic actuarial evaluation of liabilities and provide an analysis of funding levels.

The introduction of redress mechanisms for pension plan members and beneficiaries is another element that provides the proper incentives to discipline mismanagement by those responsible for the operation and oversight of the pension fund. Consumer redress may take place through informal, independent arbitration, regulatory/supervisory bodies, or through the courts. 
Transparency and disclosure of information to pension fund members is essential within any governance structure given its impact over the other elements that have been analyzed. Under these circumstances, it is clear that correct governance and a broad disclosure of the fund activities and operations are bound to restrain fund managers' and politicians' room for wrongdoing and inept management. Consequently, there is a key role to be played by transparency practices by NPPFs in order to minimize the extended conflicts of interest that have been outlined.

Information shall fulfill basic principles to make transparency and disclosure serve their purpose. These are: i) Accuracy; ii) Timeliness; iii) Relevancy; iv)User friendliness; v) Easiness of access; and vi)Effective contact information. Moreover, information disclosure should not be limited to the members of the pension plan but include an external and independent state entity to which the governing body of the NPPF may also be accountable, typically a parliament. Although there are no specific guidelines on which set of information -grounded on the above mentioned principles- should be disclosed, Bebczuk and Musalem (op.cit.) list a number of elements that should be considered as a minimum standard to be met.

\subsection{Actual governance structures}

Having provided the desirable key elements of a good governance structure for NPPFs, now we turn into the details of their actual governance practices. Evaluating all the elements regarded as desirable exceeds the scope and aim of this work, so we rather preferred to focus on a narrow set of governance characteristics that are deem to be the most relevant ones.

Therefore, and based on publicly available information at the responsible government agency, we have surveyed the actual governance structures of 83NPPFs. In the end, data was found for 80 funds. Table 2 presents the key features regarding the governing body of the NPPFs.

The Statutory Status column refers to whether the governing body of the NPPF is part of a governmental agency (inside) or has been established as a separate body (outside). In this case, information was found for 80NPPFs. Out of them, 54NPPFs representing $68 \%$ of the sample are governed by established governmental agencies, most typically the social security administration or the Minister in charge of social security affairs. Within the exceptions is the case of Nepal, where the fund is a responsibility of the Central Bank. The remaining 26NPPFs (32\%) have been established as a separate unit from the government with different degrees of independence from political intervention. This latter form for setting up the management of NPPFs does not grant full independence (since it depends upon a number of other elements) but provides the basis for effective independence.

The Size column provides information on the number of members of the governing body. In this case, we found information for $77 \mathrm{NPPFs}$ representing $93 \%$ of the surveyed sample. The average size of the governing bodies of NPPFs is 9.6 members and the median is 9 members. Notably, $14 \%$ of NPPFs are run by a single person, usually a Minister or the CEO (or similar position) of the social security agency. On the other extreme, there are a few cases having very large boards such as India (40 members) and Denmark (30 members). Good corporate governance practices recommend that decision-making powers should not be vested to a single person. Also, a decision-making body comprised by a significantly large number of people may find difficult to reach consensus and go deep into the discussion of the issues brought to the board. Having said that, it is important to remark that there is no objective and pre-determined metric regarding the optimal size of boards. The definition of this issue by each country would certainly depend upon a number of idiosyncratic elements of the NPPF.

The Representatives columns show the composition of the decision-making bodies of NPPFs. For this variable, we found information for $70 \mathrm{NPPFs}$ accounting for $84 \%$ of our sample. By far and large, the most typical arrangement is that of the so-called tripartite body, where the board has representation from the government, the employers, and the employees. Such a situation was found in 43 NPPFs that represent $73 \%$ of the NPPFs that have collegiate governing bodies. In some cases the representatives are nominated by their respective constituencies, usually a high-ranked government official (the President, Prime Minister, etc.), business associations, and labor unions. These are the cases of Costa Rica, Fiji, France, Honduras, India, Kenya, Namibia, Pakistan and Sweden (AP1, AP2, AP3, and AP4), to name but a few. In other countries, the representatives of the three constituencies are nominated and appointed at the government discretion, although some sort of consultation with the respective associations of employers and employees may be established. Bahamas, Bahrain, Malaysia, Nepal, and Philippines (SIF), among others, fall in this group.

On the other hand, solely government officials, mostly serving by virtue of their positions, constitute the boards of NPPFs inArgentina, Portugal, Spain, and Sri Lanka. Canada, Ireland and New Zealand are the most notorious examples of a third group where the board members are not appointed to represent a particular constituency but rather for their relevant professional credentialswith a clear fiduciary duty regarding the management of the 
NPPF. In most of this cases, there are also nominating committees that minimize political interference and there is a relevant role attached to the Legislative Power. The Korean fund also grants a relevant role to the National Assembly, but ultimately the decision-making powers rest with the Minister of Health and Welfare.

The last group includes different arrangements where representation is bipartite having employers and employees representatives, such as in Denmark and South Africa; or theyinclude other type of constituencies as well such as farmers, medical associations, universities, the Parliament, etc. The latter is the case for countries such as France, Guatemala, Korea, among others.

The Experts column reflects, based on publicly available information, the existence of provisions aiming at assures the presence of experts in the decision-making body. Information was found for only 16NPPFs or 19\% of the sample. Only Australia, Canada, Ireland, New Zealand and Swedish AP1, AP2, AP3 and AP4 have explicitly established such a condition for the whole board. Where a minority of the board should have relevant credentials, the Partial qualification applies; this is the case of Finland, France, Malaysia, Saint Vincent and the Grenadines, Singapore and Thailand. In other few cases (e.g., Bahrain and Saudi Arabia), we found weak indications that board members should be qualified professionals.

When assessing the professional expertise of decision-making bodies, it should also be taken into account the fact that in many cases consultative bodies, most typically Investment Committees, advise boards. Therefore, the professional credentials of the members of these committees should also be considered. Finland, Jamaica, Japan, Korea, Malaysia, Norway (GPF Global) and Swaziland are examples of NPPFs where such committees are fully made up of experts.

Finally, the Government Power column conveys information on how governments may influence the NPPF through the nomination and appointment of board members or simply that the decision-making body is composed by government officials by virtue of their position. In this case, we found information for 72NPPFs that represent $87 \%$ of our sample. If the column says "Yes", it means the government has legal powers to determine the composition of the majority or the whole of the decision-making body. This situation was found in 46 cases, representing $64 \%$ of the reduced sample. If the influence of the government is only over a minority of the decision-making body, we labeled the raw as "Partial"; $31 \%$ of the reduced sample or 22NPPFs fall under this category. The remaining 4 cases or $5 \%$ of the reduced sample are those where the government has very limited power to influence the composition of the decision-making body. This is the case where a nomination committee has been set up and/or the Parliament approval is needed for the appointment of board members. Of course, this classification is not intended to reflect what may actually happen in terms of independence of the board, but what procedures have been put in place. This category is made up of Canada, Denmark, Micronesia, and New Zealand.

\section{Transparency and Governance Indexes}

\subsection{Measuring transparency and governance: the TGI}

Attempts to link governance to NPPFs performance (Iglesias and Palacios, 2000; Mitchell et al., 2008) have relied on country governance indicators that could, but not necessarily be, correlated to the particular governance structure of NPPFs. On the other hand, Bebczuk and Musalem (op.cit.), and us have developed governance and transparency indicators exclusively for NPPFsthat are based on publicly available information only through web pages.

The development of this type of tools poses a number of challenges since they intend to quantify variables that are qualitative by nature. In the case of governmental agencies, the issue is even more problematic. Most studies have followed either two approaches, namely: a) to rely on surveys to key stakeholders; or b) to rely on publicly available information. The Governance Indicators developed by the World Bank are in the first group; while the Transparency Index for SWF developed by Carl Linaburg and Michael Maduell (Note 3), the scoreboard for comparing management practices at SWF elaborated by the Peterson Institute (Note 4), and theCentral Banks Transparency Index developed by Eijiffinger and Geraats (2006), later expanded by Dincer and Eichengreen (2009), belong to the second group.

We have followed the second approach and developed a Transparency and Governance Index (TGI). The TGI has been developed taking into account the key elements that have been identified as necessary for a good governance structure for NPPFs, while maintaining it as simple as possible so as to minimize the bias created by the subjective assessment of each fund.

The TGI draws on a tool developed by Bebczuk and Musalem (op.cit.) but further expands some of their components and modifies the structure of the index.The TGI is composed by two sub-indices, namely the 
Transparency Index (TI) and the Governance Index (GI). The former includes five elements: website, annual report, communication, information completeness, and name of responsible. The latter is composed by six elements: governing body, selection and appointment, external control, investment committee, market experts and code of conduct (see Musalem and Souto (2009) for a detailed description of each of these components).

The results of the TGI are shown in Figure 5.The range of values for the TGI is between 0 and 33. Actual figures show that the highest TGI was obtained by the Superannuation Fund of New Zealand and the Canadian Public Pension Fund (32.0 points), while on the other extreme the lowest value was 2.0 in the cases of Zimbabwe's pension fund and the two pension funds in Tunisia, the NPPF and the NSSF.

The sub-indices, namely the Transparency Index and the Governance Index are shown in Figures 6 and 7 , respectively. In the case of the Transparency Index, values may fall in the 0-15 range, while for the Governance Index the range is 0-18. In terms of transparency, 10 NPPFs exhibit a result of 2.0 points, the lowest actual figure, whilst the State Pension Fund of Finland and the Swedish AP1 and AP4 get a perfect score of 15.0.Regarding governance, three NPPF (the Zimbabwe's and the two in Ghana) exhibit a score of 0; on the other extreme, New Zealand (18.0), Canada (18.0), Swedish AP1 (14.0) and South Africa (14.0) obtained the highest governance indicators.

Table 3 presentssummary statistics for the three indexes.Also, as reflected by Table 3 and Figure 8, the TGI exhibits an asymmetric distribution with a fat left tale, making explicit that good governance and transparency standards are not widespread among NPPFs. When analyzing individual components of the TGI, the Name of Responsible and Governing Body exhibit the best results, while Code of Conduct and Market Experts show the lowest scores. Table 4 presents the mean and standard deviation for each component of the TGI.Richer countries and members of the OECD exhibit superior performance in terms of the TI, GI and the TGI, as can be seen in Table 5. A test for equality of means in the cases of the three indexes with respect to being or not an OECD country rejects the null hypothesis of equality in all situations at the $5 \%$ level of confidence.

\subsection{The TGI and its relationships with other indicators}

As it was mentioned above, a number of studies analyzed the relationship between governance and performance of NPPFs based on national indicators of governance. We contend that there might not be a high correlation among overall governance of a country and the particular governance and transparency at the NPPFs level. Hence, we analyze the correlation between our TGI and the World Bank Governance Indicators for its all six categories, namely: a) Voice and Accountability; b) Political Stability; c) Government Effectiveness; d) Regulatory Quality; e) Rule of Law; and f) Control of Corruption. The results of the correlations are presented in Table 6. As it can be seen, the correlation seems to be high for most cases, hence suggesting that overall country governance has a noticeable impact on the governance structure of NPPFs.Hence, the governance framework for a NPPF may not be dissociated from country characteristics. When analyzing the relationship between the TGI and NPPFs' size, a positive correlation is found in the case of size measured in absolute terms, but no evident relationship is present in the case of size measured in relative terms (as \% of GDP). Again, further research in this area may shed additional light on the issue.

\section{Conclusions}

A strong commitment of governments with the setting up of a good governance structure for NPPFs is needed for two main reasons. First, because of the relative importance of NPPFs in terms of assets under management which, in most cases, have no individual proprietary rights as it is the case in most privately run schemes. And second, because there is a need for a comprehensive transparency in the use of public resources that are meant to be used in the future to fulfill current promises, thereby, affecting taxation of future generations.

Ultimately, good governance is expected to deliver positive results in terms of risk-adjusted performance of the fund. In the specific case of public entities, the conventional corporate outcomes such as shareholder wealth, firm profitability and market share do not readily apply. For this reason, analysts have turned to other metrics to determine whether public sector performance is enhanced as a result of particular management practices, e.g., one outcome of interest might be investment-related.

In order to provide a quantitative tool for assessing governance and transparency structures, we have developed a Transparency and Disclosure Index using publicly available information. Based on key elements that have been so far regarded as good practices, our TGI compiles information for 83NPPFs located in 68 countries. The TGI is then a remarkable tool for further research on actual determinants of NPPFs performance, the relationship between country governance and that ofNPPFs, the role of the rule of law system, among other areas that have been mentioned throughout the document. 
From a policy point of view, the importance of the TGI is twofold. First, it serves to assess relative performance of a particular NPPF vis-a-vis its peers, and to identify areas where weaknesses exist and hence further action is called for. Second, if the TGI is to be recalculated for successive years, then policy-makers can appraise dynamic developments in the governance and transparency structure and so evaluate whether those developments have had a positive impact on the long-term performance of assets under management. In this regard, further research is needed to evaluate the impact of good governance practices on NPPF's performance.

Our analysis of the results of the TGI shows that large asymmetries exist around the globe in terms of the governance and transparency practices of NPPFs. Richest and OECD member countries show, on average, better results that the rest of the sample.

In terms of governance, a number of good practices have been advanced by international organizations, such as the ISSA and OECD, and scholars to cope with the most relevant conflicts of interest that arise in NPPFs. Independence of the governing body of the NPPFs from undue political interference and the clear definition ofthe sole objective function of NPPFs -to provide affordable and sustainable retirement income- are perhaps the most important issues that countries have to deal with.

Independence shall go hand-in-hand with accountability and professionalism. The law of fiduciary duty should define the responsibilities of boards and they should be made accountable for the performance of the fund. A transparent process for the nomination and appointment of capable boards along with clear procedures for their removal and a performance evaluation system, that not only enhances independences but strengthens accountability as well, are needed in most countries. In this sense, the traditional approach that most countries have followed in terms of a tripartite governing body -where the government, employers and employees are represented- shall be revisited and eventually reformed. Moreover, external experts should be used regularly in the definition and implementation of NPPFs policies.

An effective monitoring from outsiders and the proper functioning of accountability require high levels of transparency. In this respect, we have showed that there is large room for improvements in most countries regarding basic information such as assets under management, portfolio composition and performance. This information is not only scarce but also released with a considerable lag. The actual costs of doing so are negligible when compared to the potential benefits derived from higher levels of transparency.

We have also found that finding key pieces of information became cumbersome in a number of cases. Therefore, the presentation of such information in a user-friendly mode is essential. The development of websites for NPPFs or a special section on the websites of social security agencies are two simple ways that certain countries have chosen to improve transparency of NPPFs. However, information posted at the websites must be reliable and up-to-date in orderto be useful.

Although many NPPFs are subject to audits, these are mostly run by other governmental agencies. In weaker institutional environments, this may not be sufficient to assure that information released by the NPPFs is reliable and that internal control mechanisms are functioning properly. Hence, the introduction of performance evaluations (investment, audit, actuarial, others) conducted by external and independent entities on a regular basis should be considered as a complement that could have positive effects on transparency and accountability of governing bodies of NPPFs.

In sum, NPPFsplay a key role for the long-term sustainability of public pension plans and fiscal policy, while they are also relevant players in financial markets. Accordingly, it is required that the public pay attention to their governance structure so as to avoid misuse of the funds that would ultimately affect growth, and future and even current generations. In addition, their relative importance in world financial markets suggest that improving NPPFs governance practices, accountability and investment policies would also contribute to international financial stability. Our analysis suggests that ample room is left for reforms in most countries. Also, we have provided a framework for policy-makers to easily identify key areas where such reforms are most needed.

\section{References}

Bebczuk, R., \& Musalem, A. (2008). Public Pension Funds around the World: Governance, Investment Policies, and Performance. World Bank, Mimeo.

Bosworth, B., \& Burtless, G. (2003). Pension Reform and Saving. Brookings Institution Press.

Blundell-Wignall, A., Hu, Y., \& Yermo, J. (2008). Sovereign Wealth and Pension Fund Issues. OECD Working Paper on Insurance and Private Pensions (No. 14). 
Carmichael, J. (2002). Public Sector Governance and the Financial Sector. In Litan, R., Pomerleando, M., \& Sunderajan, V. (eds.). Financial Sector Governance: the Roles of the Public and Private Sectors. Brookings Institution Press.

Carmichael, J., \& Palacios, R. (2004). A Framework for Public Pension Fund Management. In Musalem, A. R., \& Palacios, R. (eds.). Public Pension Fund Management: Governance, Accountability, and Investment Policies. Proceedings of the Second Public Pension Fund Management Conference, World Bank.

Dincer, N., \& Eichengreen, B. (2009). Central Bank Transparency: Causes, Consequences and Updates. National Bureau of Economic Research Working Paper (No. 14791).

Eijffinger, S., \& Geraats, P. (2006). How Transparent are Central Banks?. European Journal of Political Economy, 22, 1-22. http://dx.doi.org/10.1016/j.ejpoleco.2005.09.013

Hess, D., \& Impavido, G. (2004). Governance of Public Pension Funds: Lessons from Corporate Governance and International Evidence. In Musalem, A. R., \& Palacios, R. (eds.), Public Pension Fund Management: Governance, Accountability, and Investment Policies. Proceedings of the Second Public Pension Fund Management Conference. World Bank.

Iglesias, A., \& Palacios, R. (2000). Managing Public Pension Reserves: Evidence from the International Experience. World Bank Social Protection Discussion Paper (No. 0003).

Impavido, G. (2002). On the Governance of Public Pension Fund Management. World Bank Policy Research Working Paper (No. 2878).

International Social Security Association. (2004). Guidelines for the Investment of Social Security Funds.

Maher, A. (2004). Transparency and Accountability of Public Pension Funds. In Musalem, A. R. \& Palacios, R. (eds.), Public Pension Fund Management: Governance, Accountability, and Investment Policies. Proceedings of the Second Public Pension Fund Management Conference, World Bank.

Mitchell, O., \& Hsin, P. (1994). Public Pension Fund Governance and Performance. National Bureau of Economic Research Working Paper (No. 4632).

Mitchell, O., Piggott, J., \& Kumru, C. (2008). Managing Public Investment Funds: Best Practices and New Challenges. Pension Research Council Working Paper (No. 2008-07).

Musalem, A. R., \& Palacios, R. (2004). Public Pension Fund Management: Governance, Accountability, and Investment Policies. Proceedings of the Second Public Pension Fund Management Conference, May 2003, World Bank.

Musalem, A. R., \& Souto, P. (2009). Unveiling the Governance of National Public Pension Funds. Center for Financial Stability Working Paper (No. 34).

Organization of Economic Cooperation and Development. (OECD) (2002). Revised Guidelines for Pension Fund Governance.

Palacios, R. (2002). Managing Public Pension Reserves: Lessons from Five OECD Recent Initiatives. World Bank Pension Reform Primer Working Paper series.

Useem, M., \& Mitchell, O. (2000). Holders of the Purse Strings: Governance and Performance of Public Retirement Systems. Wharton School Pension Research Council Working Paper, University of Pennsylvania.

Vittas, D., Impavido, G., \&O’Connor, R. (2008). Upgrading the Investment Policy Framework of Public Pension Funds. World Bank Policy Research Working Paper (No. 4499).

Yermo, J. (2008). Governance and Investment of Public Pension Reserve Funds in Selected OECD Countries. OECD Working Paper on Insurance and Private Pensions (No. 15).

Yermo, J., \& Marossy, A. (2002). Pension Fund Governance. Room Document of the Second OECD Conference on Private Pensions.

\section{Notes}

Note 1. Using several sources, we selected those cases were some publicly available information on the website of the NPPF or the social security agency or a similar governmental unit was found; also, language limitations applied. We acknowledge the presence of NPPFs in other countries, not included in our survey because information was not available as required for this study (e.g. Egypt, Indonesia, Kuwait, Morocco, Poland, Bahrain fund for public sector employees and military personnel, Benin, Lebanon, Saudi Arabia fund for public sector employees and military personnel, Vanuatu, Algeria, Chile, Seychelles, Zambia, Israel, Palau). Further 
efforts could be devoted to include those cases into the study in order to enrich our understanding on how NPPFs are doing around the world

Note 2. It should be noted that certain entities regarded as SWFs by the SWF Institute are also NPPFs, namely, the Superannuation Fund of New Zealand, the Global Pension Fund of Norway, and the Irish National Pension Reserve Fund.

Note 3. Available at www.swfinstitute.org

Note 4. Their taxonomy identifies four categories of management practice: i) structure; ii) governance; iii) transparency and accountability; and iv) behavior.

Table 1. Data availability for the period 2001-2007

\begin{tabular}{|c|c|c|c|c|c|c|c|c|}
\hline & & 2001 & 2002 & 2003 & 2004 & 2005 & 2006 & 2007 \\
\hline \multirow{2}{*}{ Assets } & No. of observations & 30 & 35 & 41 & 55 & 55 & 56 & 45 \\
\hline & $\%$ of total sample & 38.5 & 44.9 & 52.6 & 68.8 & 68.8 & 68.3 & 54.2 \\
\hline \multirow{2}{*}{ Portfolio } & No. of observations & 20 & 25 & 32 & $43^{r}$ & $45^{r}$ & $46^{\prime}$ & 36 \\
\hline & $\%$ of total sample & 25.6 & 32.1 & 41.0 & 53.8 & 56.3 & 56.1 & 43.4 \\
\hline \multirow{2}{*}{ Performance } & No. of observations & 17 & $21^{\prime}$ & 27 & 39 & $36^{r}$ & $35^{r}$ & 28 \\
\hline & $\%$ of total sample & 21.8 & 26.9 & 34.6 & 48.8 & 45.0 & 42.7 & 33.7 \\
\hline
\end{tabular}

Source: own elaboration 
Table 2. Key features of governing bodies

\begin{tabular}{|c|c|c|c|c|c|c|c|c|}
\hline \multirow{2}{*}{ Fund } & \multirow{2}{*}{ Statutory Status } & Size & & Represent: & atives from & & Funont & Government \\
\hline & & Size & Government & Employers & Employees & Other & Experts & power \\
\hline Argentina & Inside & 3 & 3 & & & & n/a & Yes \\
\hline Australia & Outside & 7 & & & & 7 & Strong & Yes \\
\hline Bahamas & Inside & 11 & 5 & 3 & 3 & & $\mathrm{n} / \mathrm{a}$ & Yes \\
\hline Bahrain & Inside & 15 & 9 & 3 & 3 & & Weak & Yes \\
\hline Barbados & Inside & 9 & 3 & 3 & 3 & & n/a & Yes \\
\hline Belize & Inside & 9 & 5 & 2 & 2 & & n/a & Yes \\
\hline British Virgin Islands & Inside & 7 & 3 & 2 & 2 & & n/a & Yes \\
\hline Canada & Outside & 12 & & & & 12 & Strong & No \\
\hline China & Outside & n/a & & & & & $\mathrm{n} / \mathrm{a}$ & Yes \\
\hline Colombia & Outside & 4 & 2 & & & 2 & n/a & Yes \\
\hline Costa Rica & Inside & 9 & 3 & 3 & 3 & & n/a & Partial \\
\hline Cyprus & Inside & 1 & 1 & & & & n/a & Yes \\
\hline Czech Republic & Inside & 1 & 1 & & & & n/a & Yes \\
\hline Denmark & Outside & 30 & & 15 & 15 & & n/a & No \\
\hline Ecuador & Inside & 3 & 1 & 1 & 1 & & n/a & Partial \\
\hline Fiji & Inside & 6 & 2 & 2 & 2 & & n/a & Partial \\
\hline Finland & Outside & 9 & 3 & & 3 & 3 & Partial & Yes \\
\hline France & Outside & 20 & 4 & 5 & 5 & 6 & Partial & Partial \\
\hline Gambia (FPF) & Inside & n/a & & & & & $\mathrm{n} / \mathrm{a}$ & n/a \\
\hline Gambia (NPF) & Inside & n/a & & & & & n/a & n/a \\
\hline Ghana & Inside & 14 & 6 & 2 & 2 & 4 & n/a & Partial \\
\hline Guatemala & Inside & 6 & 1 & 1 & 1 & 3 & $\mathrm{n} / \mathrm{a}$ & Partial \\
\hline Honduras & Inside & 9 & 2 & 3 & 3 & 1 & n/a & Partial \\
\hline India (EPrF) & Inside & 43 & 23 & 10 & 10 & & n/a & Partial \\
\hline India (EPeF) & Inside & 43 & 23 & 10 & 10 & & $\mathrm{n} / \mathrm{a}$ & Partial \\
\hline Ireland & Outside & 7 & 1 & & & 6 & Strong & Yes \\
\hline Jamaica & Inside & 1 & 1 & & & & $\mathrm{n} / \mathrm{a}$ & Yes \\
\hline Japan & Inside & 1 & 1 & & & & $\mathrm{n} / \mathrm{a}$ & Yes \\
\hline Jordan & Inside & 15 & 7 & 8 & 8 & & $\mathrm{n} / \mathrm{a}$ & Partial \\
\hline Kazakhstan & Inside & 1 & 1 & & & & n/a & Yes \\
\hline Kenya & Inside & 9 & 2 & 2 & 2 & 3 & $\mathrm{n} / \mathrm{a}$ & Partial \\
\hline Korea & Inside & 21 & 7 & 3 & 9 & 2 & n/a & Partial \\
\hline Latvia & Inside & 1 & 1 & & & & n/a & Yes \\
\hline Liberia & Inside & 11 & 7 & 3 & & 1 & n/a & Yes \\
\hline Malaysia & Inside & 18 & 6 & 5 & 5 & 1 & Partial & Yes \\
\hline Mauritius (NPF) & Inside & 1 & 1 & & & & $\mathrm{n} / \mathrm{a}$ & Yes \\
\hline Mauritius (NSF) & Inside & 1 & 1 & & & & n/a & Yes \\
\hline Mexico & Inside & 12 & 4 & 4 & 4 & & n/a & Partial \\
\hline Micronesia & Inside & 6 & & $\mathrm{n}$ & a & & n/a & No \\
\hline Namibia & Outside & 9 & 3 & & 3 & 3 & n/a & Partial \\
\hline Nepal & Outside & 7 & 4 & & & 3 & n/a & Yes \\
\hline New Zealand & Outside & 7 & & & & 7 & Strong & No \\
\hline Norway (GPF Global) & Inside & 1 & 1 & & & & $\mathrm{n} / \mathrm{a}$ & Yes \\
\hline Norway (GPF Norway) & Inside & 1 & 1 & & & & n/a & Yes \\
\hline Oman & Inside & 9 & 5 & 5 & 5 & & n/a & Yes \\
\hline Pakistan & Inside & 16 & 7 & 4 & 4 & 1 & n/a & Yes \\
\hline Panama & Inside & 11 & 2 & 3 & 4 & 2 & n/a & Partial \\
\hline Paraguay & Inside & 9 & 2 & 3 & 3 & 1 & n/a & Partial \\
\hline Peru & Outside & 5 & 2 & 1 & 1 & 1 & n/a & Yes \\
\hline Philippines (SIF) & Inside & 9 & & $\mathrm{n}$ & /a & & n/a & Yes \\
\hline Philippines (SSS) & Inside & 9 & & $\mathrm{n}$ & a a & & n/a & n/a \\
\hline Portugal & Inside & 3 & 3 & & & & $\mathrm{n} / \mathrm{a}$ & Yes \\
\hline Saint Kitts and Nevis & Inside & 9 & 5 & 2 & 2 & & n/a & Yes \\
\hline Saint Lucia & Inside & 7 & 3 & 2 & 2 & & $\mathrm{n} / \mathrm{a}$ & Yes \\
\hline Saint Vincent and the Grenadines & Inside & 9 & 3 & 2 & 2 & 2 & Partial & Yes \\
\hline Samoa & Inside & 10 & 2 & 3 & 2 & 3 & $\mathrm{n} / \mathrm{a}$ & Partial \\
\hline Saudi Arabia & Inside & 11 & 5 & 3 & 3 & & Weak & Yes \\
\hline Sierra Leone & Inside & 14 & 4 & 2 & 4 & 4 & $\mathrm{n} / \mathrm{a}$ & Partial \\
\hline Singapore & Inside & 15 & 2 & 2 & 2 & 9 & Partial & Partial \\
\hline Slovenia (KSPPS) & Outside & 9 & & $\mathrm{n}$ & /a & & $\mathrm{n} / \mathrm{a}$ & n/a \\
\hline Slovenia (KVPS) & Outside & 9 & & $\mathrm{n}$ & a & & $\mathrm{n} / \mathrm{a}$ & n/a \\
\hline Slovenia (PPS) & Outside & 9 & & $\mathrm{n}$ & a & & n/a & n/a \\
\hline Slovenia (SODPZ) & Outside & 9 & & $\mathrm{n}$ & /a & & n/a & n/a \\
\hline Slovenia (ZVPS) & Outside & 9 & & $\mathrm{n}$ & /a & & n/a & n/a \\
\hline South Africa & Outside & 16 & & 8 & 8 & & $\mathrm{n} / \mathrm{a}$ & Partial \\
\hline Spain & Inside & 6 & 6 & & & & n/a & Yes \\
\hline Sri Lanka & Inside & 5 & 5 & & & & n/a & Yes \\
\hline Swaziland & Outside & 12 & 3 & 3 & 3 & 3 & n/a & Yes \\
\hline Sweden (AP1) & Outside & 9 & 5 & 2 & 2 & & Strong & Yes \\
\hline Sweden (AP2) & Outside & 9 & 5 & 2 & 2 & & Strong & Yes \\
\hline Sweden (AP3) & Outside & 9 & 5 & 2 & 2 & & Strong & Yes \\
\hline Sweden (AP4) & Outside & 9 & 5 & 2 & 2 & & Strong & Yes \\
\hline Sweden (AP6) & Outside & 5 & & $\mathrm{n}$ & a & & $\mathrm{n} / \mathrm{a}$ & Yes \\
\hline Taiwan & Inside & 1 & 1 & & & & n/a & Yes \\
\hline Tanzania (NSSF) & Inside & 11 & 4 & 3 & 3 & 1 & n/a & Partial \\
\hline Tanzania (PPF) & Outside & 8 & 2 & 2 & 2 & 2 & n/a & Yes \\
\hline Thailand & Outside & 20 & 5 & 5 & 5 & 5 & Partial & Yes \\
\hline Trinidad and Tobago & Inside & 11 & 3 & 3 & 3 & 2 & n/a & Partial \\
\hline Tunisia (NPPF) & n/a & n/a & & $\mathrm{n}$ & /a & & n/a & $\mathrm{n} / \mathrm{a}$ \\
\hline Tunisia (NSSF) & n/a & n/a & & $\mathrm{n}$ & a a & & n/a & $\mathrm{n} / \mathrm{a}$ \\
\hline Uganda & Inside & 11 & & $\mathrm{n}$ & a & & n/a & Yes \\
\hline United States & Inside & 6 & 4 & & | & 2 & n/a & Yes \\
\hline Zimbabwe & n/a & n/a & & $\mathrm{n}$ & /a & & n/a & n/a \\
\hline
\end{tabular}

Source: own elaboration 
Table 3. Summary statistics for the TI, GI, and TGI

\begin{tabular}{l|ccc} 
& TI & GI & TGI \\
\hline \hline Mean & 8,7 & 6,9 & 15,6 \\
Standard deviation & 4,2 & 3,8 & 7,2 \\
Maximum & 15,0 & 18,0 & 32,0 \\
Minimum & 2,0 & 0,0 & 2,0 \\
Median & 9,0 & 7,0 & 16,0 \\
Observations & 83 & 83 & 83
\end{tabular}

Source: own elaboration

Table 4. Components of the TGI (mean and standard deviation)

\begin{tabular}{l|cc} 
& Mean & Standard Deviation \\
\hline \hline Website & 1,7 & 0,8 \\
Annual Report & 1,5 & 1,3 \\
Communication & 1,6 & 0,8 \\
Information Completeness & 1,5 & 1,2 \\
Governing Body & 2,0 & 0,8 \\
Name of responsible & 2,4 & 1,2 \\
Selection and Appointment & 1,2 & 0,8 \\
External Control & 1,7 & 1,3 \\
Investment Committee & 0,8 & 1,1 \\
Market Experts & 0,7 & 1,1 \\
Code of Conduct & 0,4 & 0,9
\end{tabular}

Source: own elaboration

Table 5. TI, GI and TGI performance per type of country

\begin{tabular}{|c|c|c|c|c|c|c|c|}
\hline & \multicolumn{2}{|c|}{ TI } & \multicolumn{2}{|c|}{ GI } & \multicolumn{2}{|c|}{ TGI } & \multirow[b]{2}{*}{ Observations } \\
\hline & Mean & $\begin{array}{l}\text { Standard } \\
\text { deviation }\end{array}$ & Mean & $\begin{array}{l}\text { Standard } \\
\text { deviation }\end{array}$ & Mean & $\begin{array}{c}\text { Standard } \\
\text { deviation }\end{array}$ & \\
\hline$\overline{\mathrm{OECD}}$ & 12,6 & 3,2 & 9,9 & 44,1 & 22,5 & 6,2 & 21 \\
\hline Non-OECD. & 7,4 & $3,7$. & 5,9 & 3,1 & 13,2 & $5, \underline{9}$. & 62 \\
\hline High income & 10,6 & 4,5 & 8,0 & 4,1 & 18,6 & 7,7 & 35 \\
\hline Upper middle income & 7,8 & 3,7 & 7,8 & 3,5 & 15,6 & 5,7 & 16 \\
\hline Lower middle income & 7,1 & 3,4 & 5,8 & 3,3 & 12,9 & 6,1 & 20 \\
\hline Low income & 6,7 & 3,5 & 4,4 & 2,4 & 11,1 & 5,7 & 12 \\
\hline
\end{tabular}

Source: own elaboration

Table 6. TGI and WB Governance Indicators 2007 (correlation coefficients)

\begin{tabular}{c|cccccc} 
& $\begin{array}{c}\text { Voice and } \\
\text { Accountability }\end{array}$ & $\begin{array}{c}\text { Political } \\
\text { Stability }\end{array}$ & $\begin{array}{c}\text { Government } \\
\text { Effectiveness }\end{array}$ & $\begin{array}{c}\text { Regulatory } \\
\text { Quality }\end{array}$ & Rule of Law & $\begin{array}{c}\text { Control of } \\
\text { Corruption }\end{array}$ \\
\hline TI & 0,53 & 0,42 & 0,55 & 0,54 & 0,52 & 0,58 \\
GI & 0,51 & 0,41 & 0,44 & 0,46 & 0,44 & 0,51 \\
TGI & 0,58 & 0,46 & 0,55 & 0,56 & 0,53 & 0,61
\end{tabular}

Source: own elaboration 


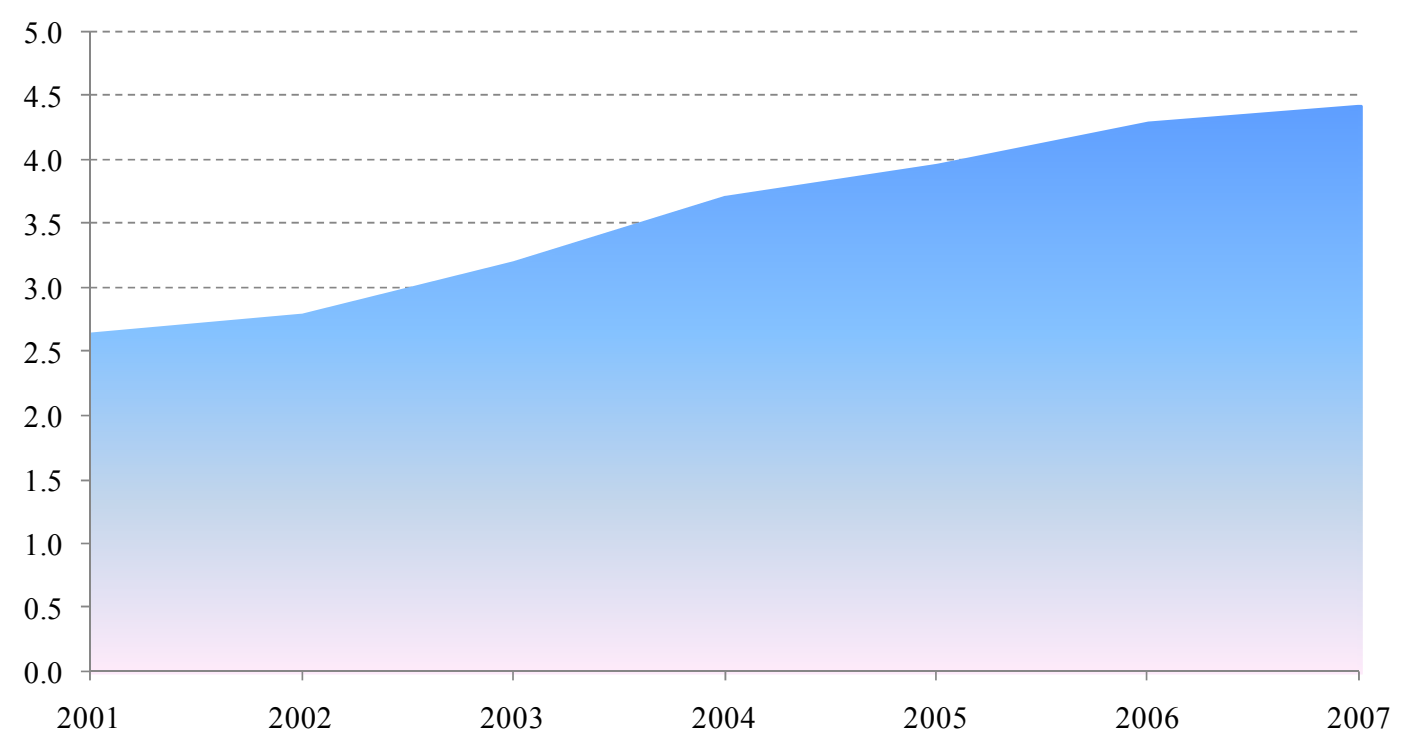

Figure 1. Assets under management 2001-2007 (in USD trillions)

Source: own elaboration based on official NPPF websites

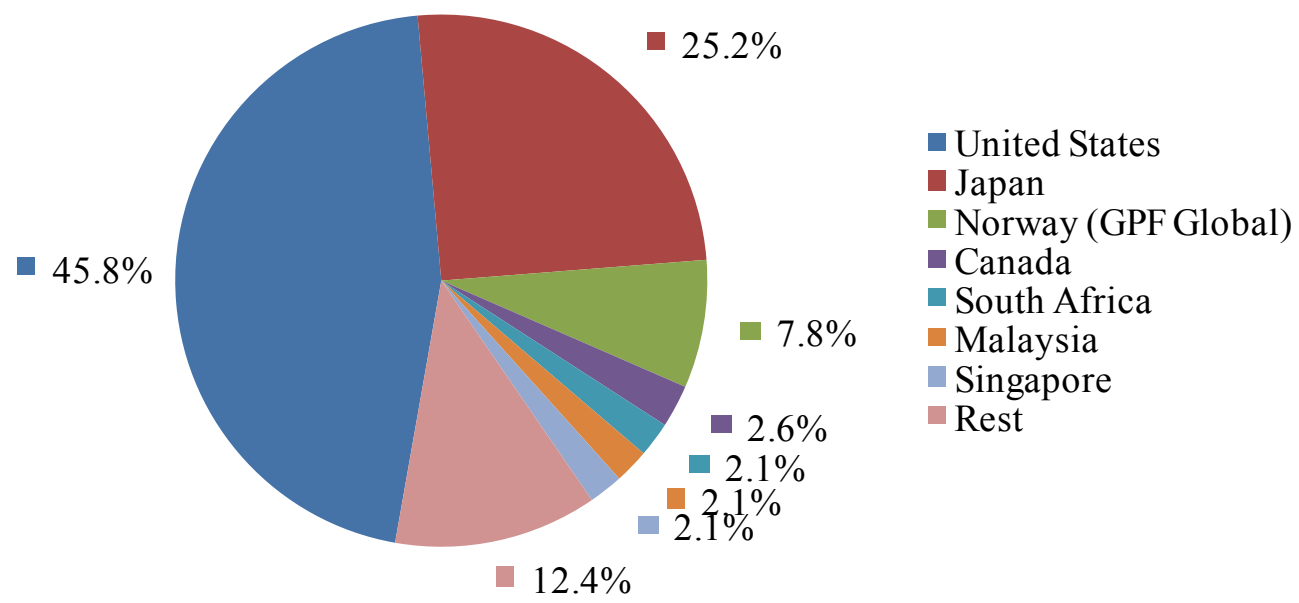

Figure 2. Concentration of assets under management (2007)

Source: own elaboration based on official NPPF websites 


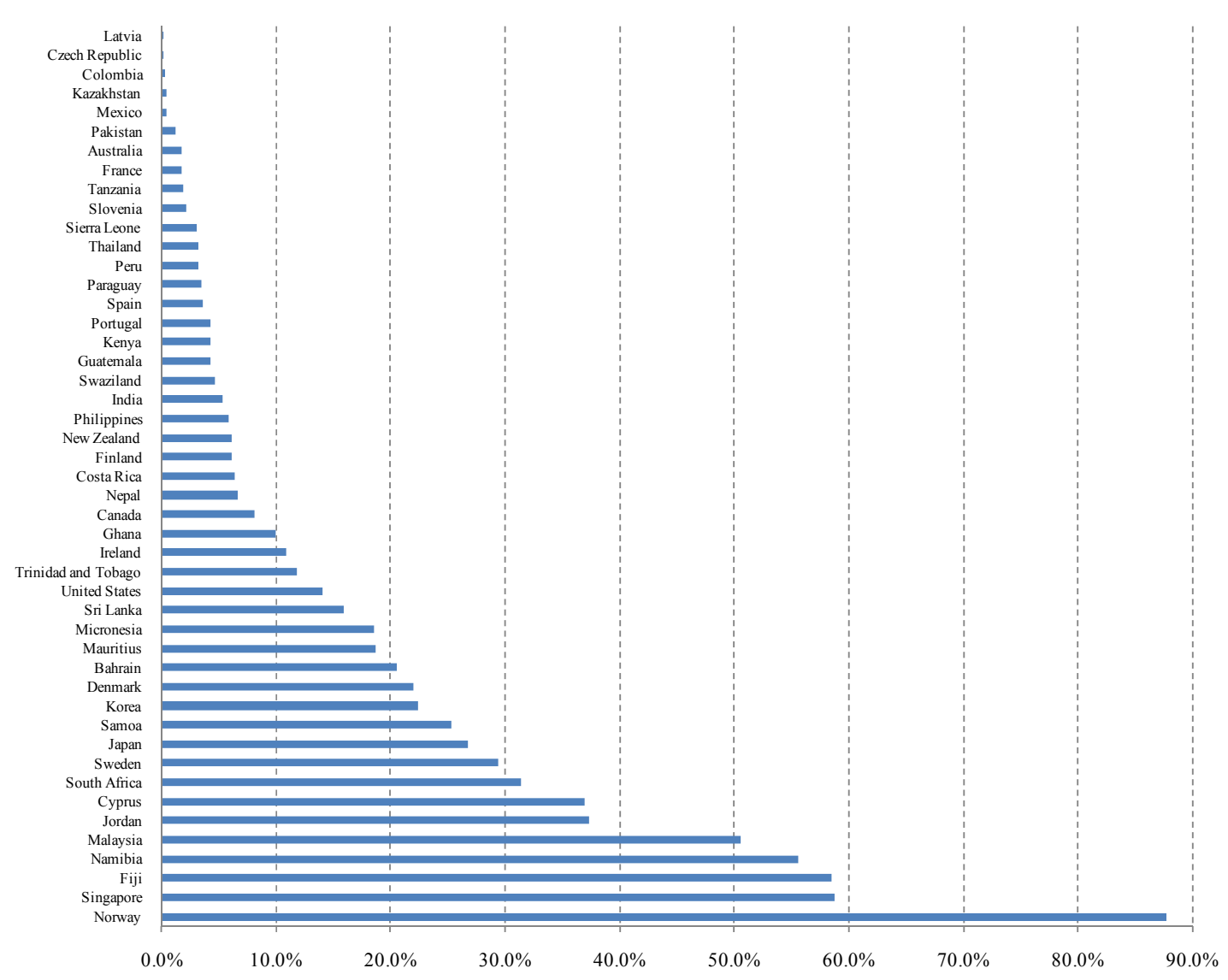

Figure 3. Assets under management in 2006 (as \% of GDP)

Source: own elaboration based on official NPPF websites

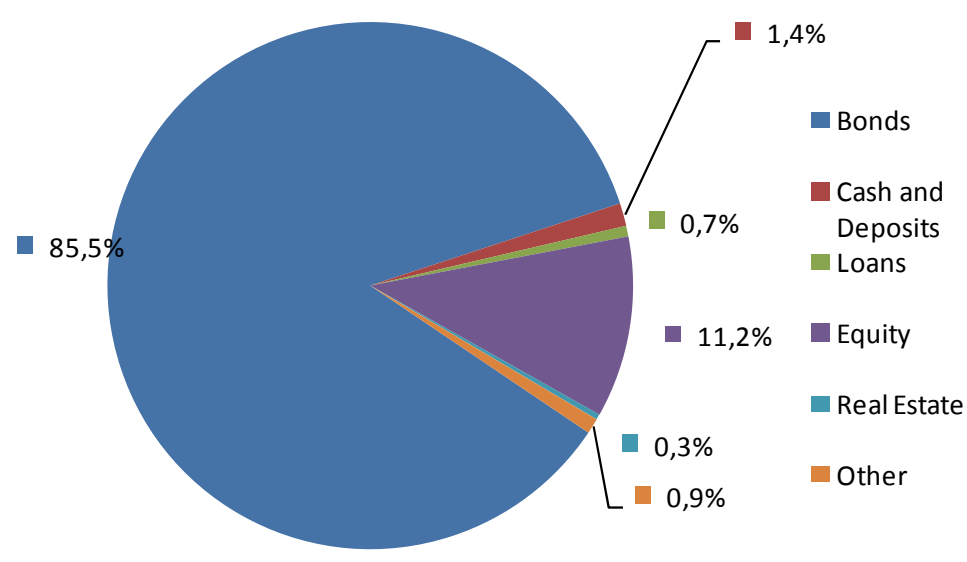

Figure 4. Composition of the investment portfolio (2001-2007 weighted average)

Source: own elaboration based on official NPPF websites 


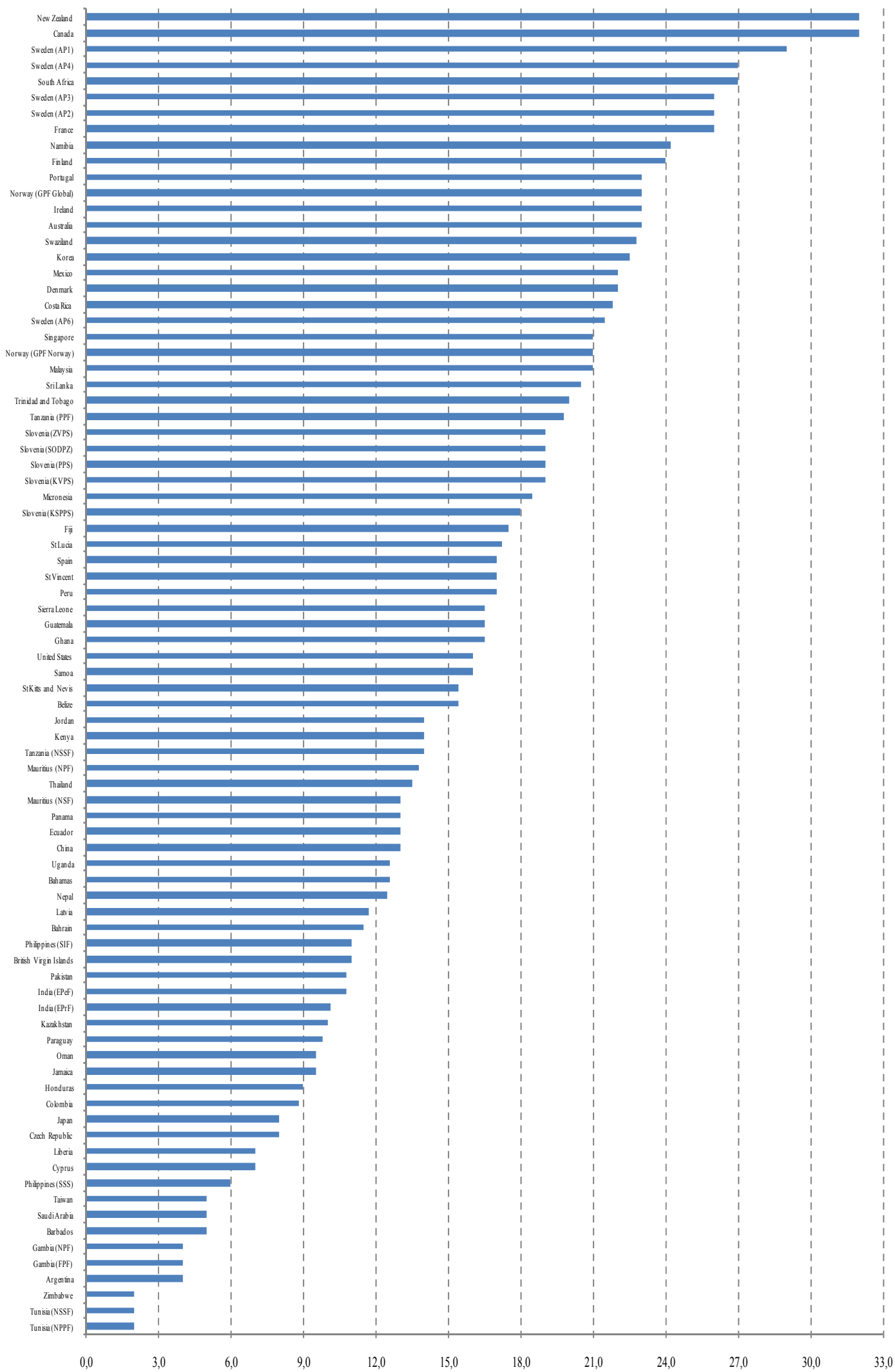

Figure 5. Transparency and Governance Index (TGI)

Source: own elaboration 


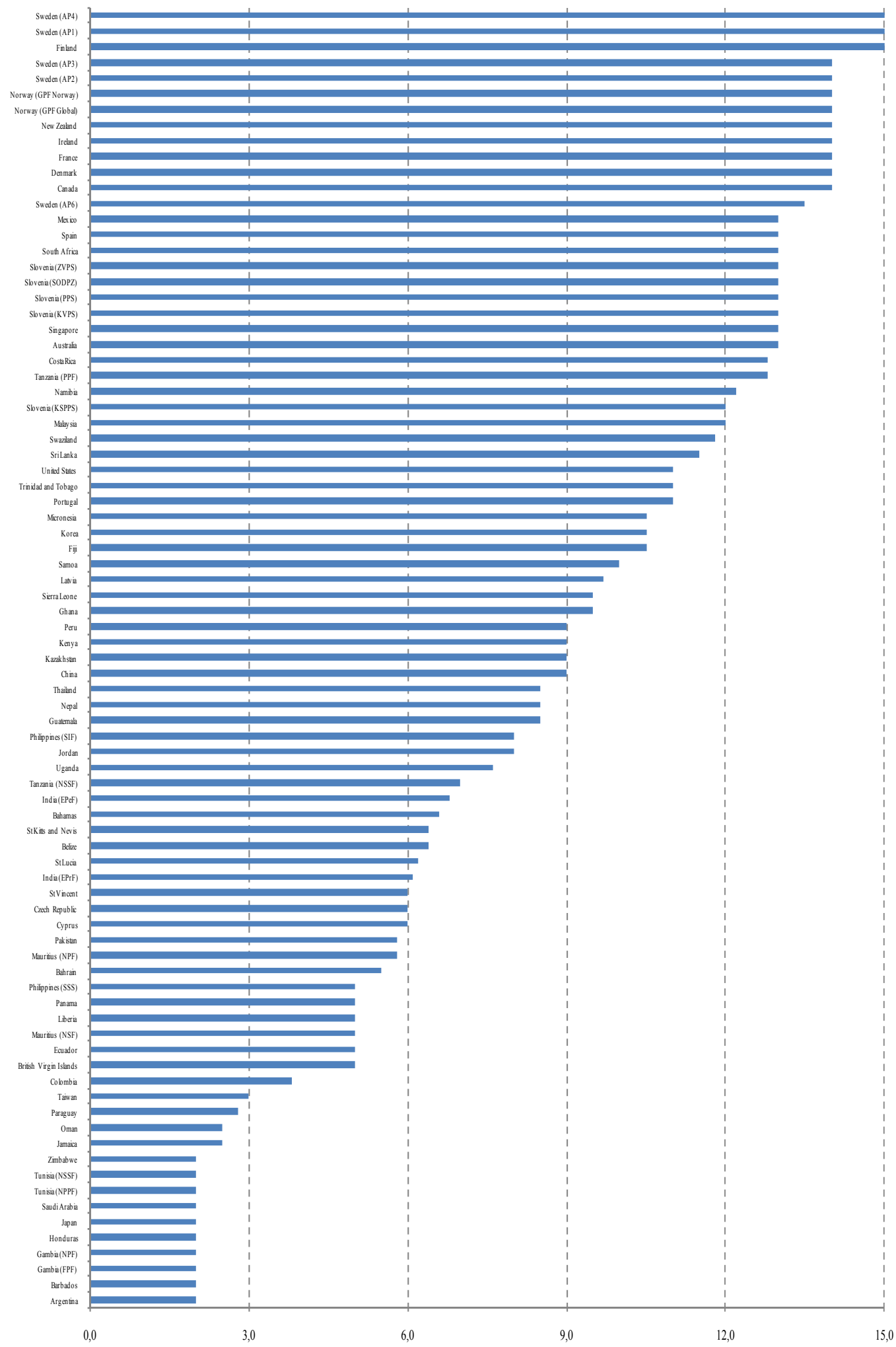

Figure 6. Transparency Index (TI)

Source: own elaboration 


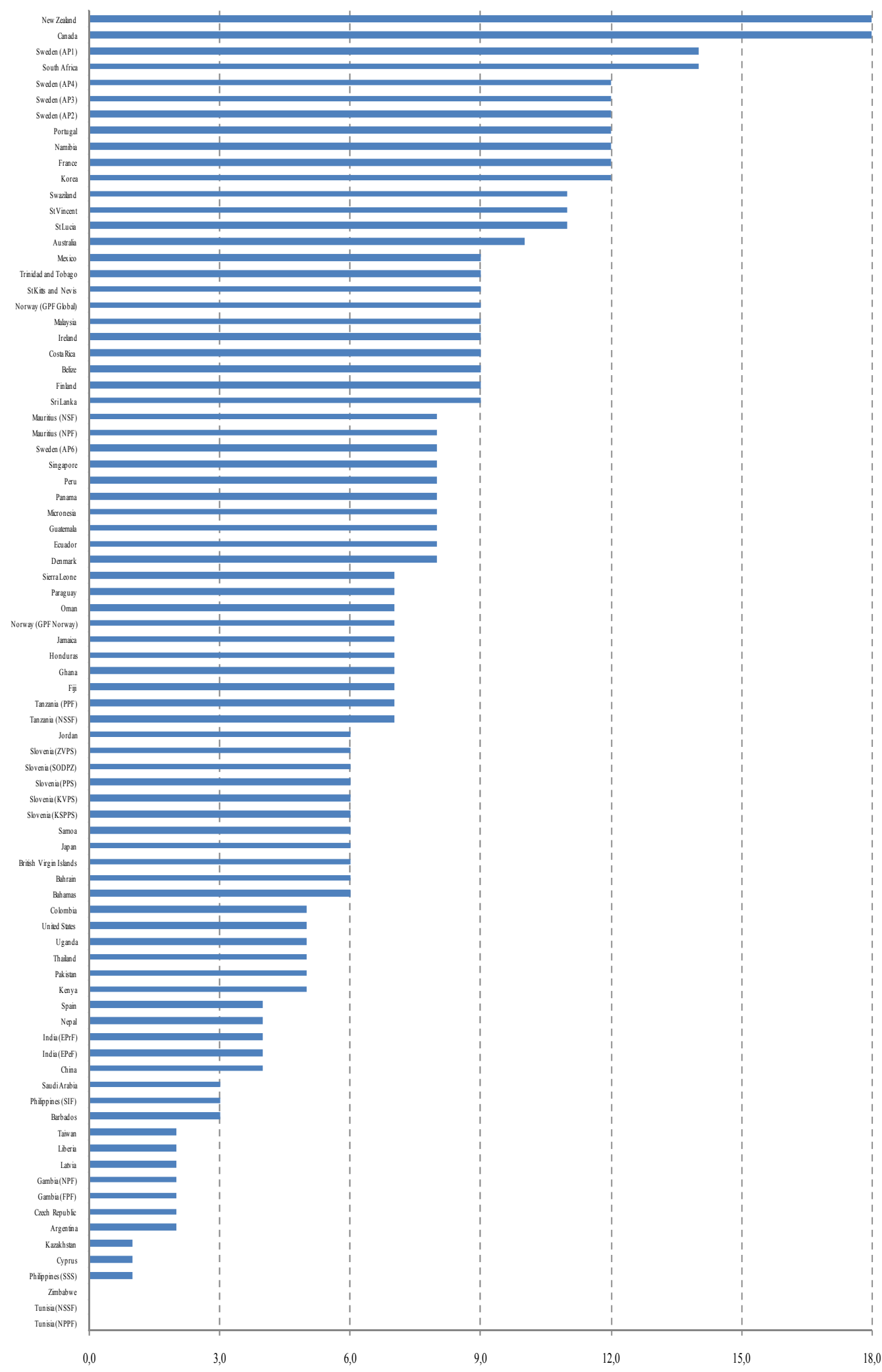

Figure 7. Governance Index (GI)

Source: own elaboration 


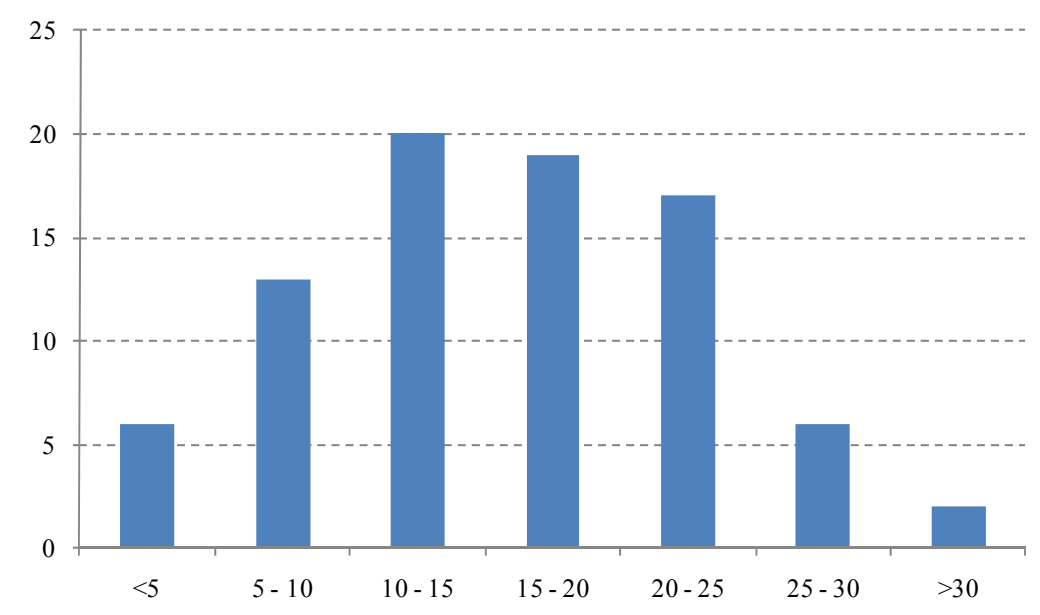

Figure 8. Frequency distributions of the TGI

Source: own elaboration 